\title{
Increasing physical literacy in youth: A two-week Sport for Development program for children aged 6-10
}

\author{
Marika Warner ${ }^{1} \cdot$ Jackie Robinson $^{1} \cdot$ Bryan Heal $^{1} \cdot$ Jennifer Lloyd $^{2} \cdot$ \\ James Mandigo $^{3} \cdot$ Bess Lennox $^{4} \cdot$ Larkin Davenport Huyer $^{5}$
}

Accepted: 1 September 2020 / Published online: 2 November 2020

(C) The Author(s) 2020

\begin{abstract}
Regular physical activity significantly improves health outcomes, yet rates of childhood physical activity remain alarmingly low. Physical literacy has been identified as the foundation for quality physical education, suggesting that sport, education, and
\end{abstract}

The authors wish to acknowledge MLSE LaunchPad's youth members and their families, the entire MLSE LaunchPad staff team, the MLSE Foundation, and MLSE for their commitment and support.

Marika Warner

marika.warner@mlselaunchpad.org

Jackie Robinson

jackie.robinson@mlselaunchpad.org

Bryan Heal

bryan.heal@mlselaunchpad.org

Jennifer Lloyd

jenniferalloyd92@gmail.com

James Mandigo

james.mandigo@ufv.ca

Bess Lennox

bess.lennox@mlselaunchpad.org

Larkin Davenport Huyer

larkinhdh@gmail.com

1 Department of Research and Evaluation, MLSE LaunchPad, 259 Jarvis Street, Toronto, ON M5C 2B2, Canada

2 Faculty of Social Work, Wilfrid Laurier University, 75 University Avenue West, Waterloo, ON N2L 3C5, Canada

3 University of the Fraser Valley, 33844 King Road, Abbotsford, BC V2S 7M8, Canada

4 Department of Sport Programming, MLSE LaunchPad, 259 Jarvis Street, Toronto, ON M5C 2B2, Canada

5 Department of Public Health Sciences, Queens University, Carruthers Hall, 2nd and 3rd Floors, 62 Fifth Field Company Lane, Kingston, ON K7L 3N6, Canada 
public health interventions should seek to increase physical literacy to promote physical activity. A two-week day camp program for children aged 6-10 facing barriers to positive development, was developed and delivered by a Sport for Development facility in Toronto, Canada. Utilizing fundamental movement skills (FMS) as a teaching tool and a pre- and post-assessment, the camp aimed to increase physical literacy and promote engagement in physical activity. Results indicate a significant increase in FMS (t $(44)=4.37, p<.001)$ as well as improved self-perceptions of physical literacy ( $\mathrm{t}(40)=14.96, p<.001)$. The largest FMS increases were found in running and balance and the most significant impacts were among low baseline performers.

Keywords Physical literacy - Sport for Development · Fundamental movement skills · Youth · Physical activity

Building a shared understanding of how to effectively promote lifelong engagement in physical activity (PA) through the development of physical literacy (PL) is an important aim for the sport, youth service, and education sectors, both in Canada and internationally (Mandigo et al. 2018). PL has been identified as the foundation of quality physical education in UNESCO's (2015) guidelines for policy makers, and it continues to gain credibility and momentum as an educational concept and programming objective for PA and sport providers and in broader public health interventions (Edwards et al. 2017; Edwards et al. 2018; Mandigo et al. 2009; O’Brien et al. 2015; Tremblay et al. 2018). Previous research by Whitehead (2010) has described PL as a multifaceted concept, including a range of skills required for an individual to fully realize their experienced PA potential. More recently, PL has been defined by the International Physical Literacy Association as the motivation, confidence, physical competence, knowledge, and understanding to value and take responsibility for engagement in physical activities for life (Tremblay et al. 2018). Alternative definitions offer similar conceptualizations, including elements of confidence, competence/ability, motivation/desire, and the knowledge/understanding needed to be active on an ongoing basis (Longmuir and Tremblay 2016; O'Brien et al. 2015). PL has also been conceptualized as a determinant of health, with considerable implications relating to PA, motor skill outcomes, and social and affective learning processes (Cairney et al. 2019). The acquisition of fundamental movement skills (FMS) and regular ongoing participation in PA are essential components in the lifelong development of PL (Cairney et al. 2019; Haywood and Getchell 2009; O’Brien et al. 2015; Tompsett et al. 2014).

FMS constitute a bank of movement competencies (Whitehead 2010) that contribute to the competence component of PL and are prerequisites to becoming physically literate (O'Brien et al. 2015). FMS have been independently associated with a range of positive health-related outcomes (Logan et al. 2012). They include a range of basic movement skills falling into several domains: running/locomotor; object control or manipulation, including upper and lower body; and balance, stability, and body control (Canadian Sport for Life 2014a; Dudley 2015). With a foundation of FMS, youth may go on to develop more complex and sport-specific movement skills, thus potentially building greater confidence and motivation to participate in PA (Canadian Sport for Life 2017; Dudley 2015). Community sport and public health interventions designed to increase PL, especially among youth, frequently utilize FMS as a primary teaching tool and intended outcome (Logan et al. 2012; O'Brien et al. 2015). 
Despite the increased focus on PL as a vital outcome, impacting the health and wellbeing of all children and youth, childhood PA levels remain alarmingly low in Canada and elsewhere (Barnes et al. 2016). In countries that report robust infrastructure such as Canada, youth appear to engage in increased sedentary behavior and decreased PA compared to other regions (Mitra et al. 2017; Tremblay et al. 2016). PL may be viewed as an enabling, predisposing, and reinforcing factor for PA (Edwards et al. 2017; Giblin et al. 2014; O'Brien et al. 2015; Tompsett et al. 2014;), affecting subsequent health outcomes related to adiposity, fitness, cardiometabolic health, and social and emotional health (Cairney et al. 2019; Carson et al. 2017; Edwards et al. 2017; Poitras et al. 2016). PA also affects educational outcomes related to cognitive performance (Castelli et al. 2014; Donnelly et al. 2009). Low levels of PL are likely to contribute to and compound the issue of low PA; without adequate physical competence, confidence, motivation, and knowledge, children and youth are less likely to engage in PA at sufficient levels. The long-term consequences of this are significant, as regular PA participation is known to significantly improve physical and mental health outcomes in childhood, adolescence, and adulthood (Dobbins et al. 2013; Physical Activity Guidelines Advisory Committee 2008; Rauner et al. 2013). The prominence of physical inactivity among children and youth is similarly associated with a variety of negative physical, psychological, and social health indicators and chronic conditions (Coyne et al. 2019a, b).

Based on the current 24-hour movement guidelines for Canadian children and youth, children aged 5-17 years require 60 minutes per day of moderate to vigorous physical activity (MVPA) (Tremblay, Carson et al. 2016), but on average only 9\% accumulate these active minutes (Barnes et al. 2016). Increased PL is likely to foster the achievement of this benchmark. As levels of PA are known to decline dramatically during adolescence, alongside an increase in the prevalence of chronic disease risk factors, it is important that a foundational level of PL is achieved prior to adolescence, to facilitate continued participation in sport and PA during adolescence and emerging adulthood (Barnes et al. 2016; Dudley 2015; Tompsett et al. 2014). Available data indicate that the average PL levels of youth in Canada match the low levels of PA reported: the 2018 ParticipACTION report card assigned a grade of "D+" for both overall PA and PL, indicating that 21-40\% of Canadians aged 3-17 meet benchmarks for these indicators (ParticipACTION 2018).

One contextual factor likely to contribute to low PA levels, particularly among youth facing barriers, is a lack of access to high-quality programs designed to introduce FMS and develop PL. Community sport programs tend to focus on sport-specific skills and gameplay. Curricula and implementation may not adequately address high-priority outcomes, including the development of PL. Many community sport programs also present financial and other obstacles to participation (Bassett-Gunter et al. 2017; Canadian Heritage 2013; CIBC and KidSport 2014; Government of Ontario 2015; Wright et al. 2017). Sport for Development (SFD) has been defined as the intentional use of sport and PA as tools to bring about positive change in the lives of people and communities (Sported 2020). SFD programs focus on social inclusion and are likely to be more accessible to youth facing barriers, but PL has also not traditionally been viewed as an intended outcome of SFD. SFD interventions typically target positive youth outcomes relating to education and/or socialemotional outcomes (Schulenkorf et al. 2016; Svensson and Woods 2017; Whitley et al. 2017, 2019c). However, based on the definitions outlined above, PL may be considered as both a positive youth development outcome and a life skill that is likely to create long-term impacts for individual youth, families, and communities.

Another important factor impacting levels of PA and PL among Canadian children and youth, particularly those who face added barriers to positive development, is the ongoing 
erosion of physical education programming in public school settings (Hobin et al. 2017; Trudeau and Shephard 2008). Decreased or otherwise compromised delivery of such programs disproportionately impacts youth facing challenges such as low socioeconomic status (Leblanc et al. 2015), increasing the need for high-quality physical activity programs delivered in a community setting (Green et al. 2018).

Among community sport and SFD programs that intentionally design and deliver programs to address PL, promising and best practices for program development and implementation have not been thoroughly documented or well communicated within the sector (Lyras and Welty Peachy 2011). Useful evidence to guide high-quality program design, delivery, and evaluation is more readily available in the sports medicine and physical education literature (Barnas and Ball 2019; Belanger et al. 2016; Durden-Myers et al. 2018; Edwards et al. 2017; Hennessy et al. 2018). A communication gap between researchers and practitioners creates an obstacle to the delivery of evidence-based programming. The staff teams of program delivery organizations do not typically include researchers or evaluators, and there is a lack of rigorous measurement in the program delivery setting to determine and define the impact of programs on PL and related outcomes (Whitley et al. 2019a). In some cases, evidence-based curricula that could be utilized as a sectoral best practice is seen as private or proprietary material and is not shared freely and publicly within the sector (Whitley et al. 2019a, 2019b).

This paper presents initial evidence that an intentionally designed two-week SFD day camp program successfully increased PL among youth facing barriers in a North American urban context, and explores the methodology used to teach and evaluate PL at a community-based SFD facility.

\section{Physical literacy policy and intervention overview}

Evidence supports school-based physical education (PE) as an opportune window for the promotion and development of PL (Dudley 2015; O'Brien et al. 2015). An appropriate PE curriculum has the potential to engage students in PA while also preparing them to apply PL beyond the school setting (Ennis 2015). However, PE programs alone do not provide adequate MVPA to meet recommended guidelines and, in fact, make only a small contribution to helping children achieve these benchmarks (Castelli et al. 2014; Johnstone et al. 2019). Additionally, the current political climate in Ontario (Canada) and elsewhere has led to the erosion of PE programs: staffing has decreased, fewer hours are dedicated to PE, and some elementary schools have completely cancelled PE programs (Draaisma and Brown 2018; McGinn 2016). This climate challenges community sport and SFD providers to offer programs in the after-school hours, to fill this gap and provide extended, expanded, and enhanced opportunities for youth PA (Beets et al. 2016).

Evidence suggests that before- or after-school programs, provided in community settings with a caring and empowering climate, may also serve as logical and impactful points of intervention to provide increased opportunities for PA participation and the development of PL (Castelli et al. 2014; Edwards et al. 2018; Johnstone et al. 2019). Pedagogical strategies and program practices recommended for these contexts include maximizing MVPA, making connections to the community, using program activities to refine motor competencies, and encouraging interest-based engagement in PA (Castelli et al. 2014). 
Scientific evidence demonstrating the efficacy of PL interventions is limited (Giblin et al. 2014; Johnstone et al. 2019; Shearer et al. 2018), although significant improvements in FMS have resulted from motor skill program interventions with young children (Logan et al. 2012). A proposed model for PL policy stresses that the promotion and development of FMS should not occur at the expense of broader lifelong PA pursuits and opportunities, and that particularly for youth, the development of movement skills should be broad and diverse (Dudley et al. 2017). Practically, this suggests implementing programs that include content relating to a variety of sports, games, and physical activities. The flexible application of physical skills to a variety of functional contexts outside of the gymnasium should also be a program feature. These approaches will help to foster the enjoyment of PA, an underlying component of PL (Ennis 2015). Inconsistencies in the definition and operationalization of PL have also negatively impacted clarity in intervention design. It is recommended that programming organizations adopt a clear operational definition of PL, appropriate to their context, to provide a basis for the design of program curriculum and evaluation (Edwards et al. 2018; Shearer et al. 2018).

The development and adoption of integrated and philosophically aligned approaches to assessing PL, along with the use of formative assessment strategies which use assessment to inform learning approaches, are recommended in the evaluation of PL programs (Edwards et al. 2018; Shearer et al. 2018; Tompsett et al. 2014). PL assessments should test the self-regulated execution of gross motor coordination in a range of tasks to measure individuals' strengths and weaknesses, including specific evidence of skill progression to track development over time (Giblin et al. 2014). While the adoption of quantitative assessments of PL may help coaches identify areas for improvement, plan interventions tailored to groups and individuals, and track progress over time (Edwards et al. 2018), there is a documented lack of robust empirical tools to assess the physical competence component of PL (Longmuir and Tremblay 2016). Requirements for time, space, and equipment; a clinical or deficit-oriented approach; and tester bias have been identified as significant issues impacting the utility of existing physical competence assessments (Giblin et al. 2014; Longmuir and Tremblay 2016).

\section{Sport for development and physical literacy}

SFD programs focusing on health-related outcomes, including PL, generally fall into one of two categories: sport plus or plus sport (LeCrom et al. 2019). Sport plus programs prioritize sport as a tool and context for learning and development. In contract, plus sport programs primarily focus on a social or health issue and utilize sport as one means to achieve youth development outcomes. As the strategic use of sport may address a range of issues, health-related and otherwise, both approaches may be applicable for health-focused SFD programming, including programs designed to increase PL (LeCrom et al. 2019). However, the evidence supporting the ability of sport to promote health outcomes primarily addresses sport participation generally, not the strategic application of sport in the SFD setting.

The ability of a sport program to positively impact health outcomes is context-dependent (LeCrom et al. 2019). Specifically, to support youth's journey to achieve PL, a program setting must engage them personally, socially, and physically (Dudley 2015). The personal and social attributes of movement described by Hellison (2003) include several positive youth development outcomes typically associated with SFD programs, including peaceful conflict resolution, inclusion, the courage to persist, self-motivation, leadership, and inner 
strength. These components of social responsibility are described as potential benefits that may be achieved through intentional PA, so they create a theoretical path connecting a movement-rich PL program to SFD outcomes. The SFD approach also supports improved health outcomes by facilitating increased access to sport opportunities for youth facing barriers (LeCrom et al. 2019).

Previous evidence recommends a strategic and specific focus for SFD programs that intend to document a positive impact on health outcomes (LeCrom et al. 2019). Additional best practices for SFD programs that address health outcomes include the presence of caring and nurturing leaders, coaching or mentoring by peers, well-trained staff and volunteers, organizational consensus regarding the organization's goals and model of development, interactive games that support health promotion objectives, and parental/community support (LeCrom et al. 2019).

\section{Gaps in the literature}

To date, research attempting to measure PL is scarce (Edwards et al. 2018) particularly in community sport and SFD settings, and the connection between SFD and health-related outcomes including PL is an under-researched phenomenon (Whitley et al. 2017, 2019c). In published studies measuring PL quantitatively, quality of movement has not often been assessed (Edwards et al. 2018). Although much effort has been made to create and validate tools for measuring PL in children (Edwards et al. 2018; Giblin et al. 2014; Lodewyk and Mandigo 2017; Mandigo et al. 2018), little exploration of what measures or assessments are most appropriate for various age groups and settings has been documented (Edwards et al. 2018; Longmuir and Tremblay 2016). There is also a documented need to develop more creative approaches to measure PL through non-conventional methods (Edwards et al. 2018).

\section{Methods}

\section{Participants}

Participants consisted of children aged 6-10 years. All participants were members of MLSE (Maple Leaf Sport and Entertainment) LaunchPad, a SFD facility for youth facing barriers aged 6-29. Youth facing barriers are defined by MLSE LaunchPad as youth who may require greater supports and services to reach their full potential. In the context of downtown Toronto, Canada, this definition includes racialized youth, Indigenous youth, low-income youth, youth with disabilities, homeless or under-housed youth, youth in care or leaving care, 2SLGBTQ youth, newcomer youth, and youth in conflict with the law. No formal process is used at MLSE LaunchPad to ensure that youth accessing their programs and services meet these criteria, and no youth are excluded from participation based on these criteria. However, the neighborhood demographics and outreach strategies have to date resulted in program participation primarily by youth who meet the criteria described. Demographic data collected from youth members at MLSE LaunchPad indicate that of $\sim 9000$ members, $88.67 \%$ identify as racialized youth, with the most significant representation among Black youth at $33.83 \% .76 .76 \%$ of youth report an annual household 
income less than $\$ 30,000$, below the low-income cut-off for a family of 3 in the province of Ontario. Participant demographics for the current study are detailed below in Results.

\section{Recruitment}

We recruited youth on day 1 of the program. Upon checking into the facility, we approached parents/guardians and youth, and explained the purpose and procedures of the study, provided written information, and offered parents/guardians the opportunity to provide their informed consent through a written form. Then, we offered youth the opportunity to provide informed assent by signing a separate form. Both informed consent by the parent/guardian and informed assent by the youth were requirements of participation in the study. The Community Research Ethics Office approved all procedures.

\section{Intervention}

MLSE LaunchPad developed the intervention in 2019. The intervention was delivered at MLSE LaunchPad, a large SFD facility located in downtown Toronto, Canada, that offers free programming to youth facing barriers to positive development, aged 6-29. All programs and services align with MLSE LaunchPad's Theory of Change, included below as Figure 1 . The facility is a newly renovated $\sim 42,000$ square foot space that includes three sport courts, a multi-purpose atrium, three classrooms, a rock-climbing wall, and an industrial kitchen. The facility offers a supportive, welcoming, and inclusive environment and provides a variety of wraparound services to meet the needs of members, including mental health counseling, academic supports, nutrition programs, and access to youth mentors.

The concept of PL was foundational to the intervention. PL was operationally defined as having the motivation, confidence, competence, and knowledge to be physically active for life (Tremblay et al. 2018). The development of both FMS and enjoyment of PA were considered key to achieving gains in PL. The 2-week day camp program was specifically developed to promote PL among youth aged 6-10 who face a variety of barriers to positive development, including racialized youth, newcomer youth, and low-income youth. The program used FMS activities, sport-specific activities (including gameplay and featuring

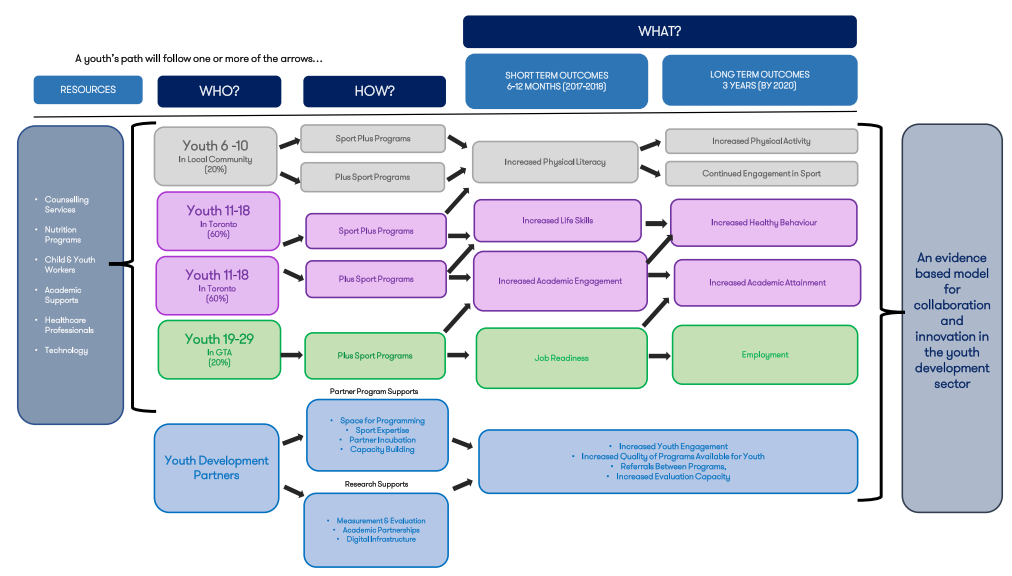

Figure 1 MLSE LaunchPad's theory of change 
both individual and team sports), games of low organization, and low-to-no-cost PA-based field trips - for example, to the local playground - to develop PL. The program consisted of 9 full days of programming, as the facility was closed for one day during the 2-week period to observe a national holiday. On days 1 and 9, youth participated in a 'carnivalstyle' FMS assessment to assess the performance of 13 FMS. They also completed a selfreport PL survey on days 1 and 9 as part of the assessment. The outcome measures and data collection procedures are fully described below under Measurement Tools and Data Collection.

Programming began at 8:30 AM with 30 minutes of supervised free play; basketballs and nets, soccer balls and nets, and ball hockey equipment were provided. Staff participated in free play alongside youth and encouraged but did not lead or structure the activity. After a brief sedentary session from 9:00-9:15 AM to introduce the plan for the day and review group rules, youth participated in $\sim 1$ hour of structured PA, followed by a mid-morning snack at $\sim 10: 15$ AM. Morning activities included a rotation of games of low organization with new games introduced each day, and sport-specific skill development including rock climbing, basketball, rugby, European handball, dance, soccer, and volleyball. Following the morning snack break, youth participated in $~ 90$ minutes of active play in small groups, including a variety of games of low organization incorporating FMS. Lunch was served from 12:30-1:15 PM, followed by a brief sedentary session to introduce the next series of activities. From 1:30-3:30 PM (with a 15-minute afternoon snack break at $2: 45$ PM), youth engaged in a series of rotational activities in small groups that included games of low organization, activities focusing on specific domains of FMS such as balance, physically active team-building activities such as a blindfolded obstacle course, and sport-specific activities (skills, drills, and gameplay), including badminton, basketball, soccer, dance, and ball hockey. The final session of the day, from 3:30-4:00 PM incorporated FMS into a large-group structured activity such as FMS tag or FMS dance, and each day concluded with a group cheer. Throughout the day, brief periods of sedentary activity were incorporated to provide an appropriate balance of activity levels, reflecting the 24-hour movement guidelines for Canadian children and youth (Tremblay, Carson et al. 2016).

The camp included three field trips, one each to an aquarium, a museum featuring a sport-related exhibit, and a neighborhood playground. A combination of active transportation (walking), paid transportation (chartered bus), and public transit (subway) was incorporated to transport participants to and from field trip locations. Throughout the 9-day camp, a total of 7 sedentary activity sessions were included, outside of brief periods used to introduce upcoming activities each morning and following the lunch break. They were a craft activity, a nature activity, an activity relating to healthy eating and environmental sustainability, 2 STEM (Science, Technology, Engineering, and Math) activities, and two teambuilding activities. Each of these sedentary activities had a duration of 45-60 minutes. Off-court activities focused on overall wellbeing and fun. Overall, youth engaged in 200-285 minutes of physical activity each day.

The design and delivery of the intervention were intentionally aligned with a clear operational definition of PL: having the motivation, confidence, competence, and knowledge to be physically active for life (Tremblay et al. 2018). Key program characteristics reflective of this chosen definition included a variety of interest-based activity options and opportunities for choice and autonomy to enhance motivation; developmentally-appropriate progressions, a focus on positive peer and adult relationships, and a welcoming and inclusive program environment to foster confidence; a mastery-oriented approach to both FMS and sport-specific skills to develop competence; and discussions and debriefs connected to sport activities to help build sport-related knowledge (Cale and Harris 2018; Liu 
et al. 2017). The evidence-based SFD curriculum consisted of various activities and positive development opportunities, which emphasized physical literacy while supporting the overall development of youth facing barriers aged 6-10 (Bopp and Roetert, 2018).

30 on-duty staff were required. Staff included a combination of 20 "Leaders in Training" (youth aged 14-18 participating in a paid summer employment program) and ten permanent part-time or full-time staff. Staff credentials included a variety of nationally recognized coaching certifications. Staff were primarily hired from the local community and were reflective of participant demographics.

\section{Measurement tools and data collection}

The LaunchPad Fundamental Movement Skills Assessment was used to provide an observed rating of the competence component of PL. This assessment was created by MLSE LaunchPad and has been utilized in regular year-round programming since September 2018, and it is currently undergoing validation. The assessment draws from the PLAYfun tool developed by Sport for Life (2014a), with several modifications to increase feasibility and utility in a SFD setting. Each of the 13 FMS were used by participants in the performance of intervention activities, but not specifically taught, coached, or drilled. The assessment evaluates performance on 13 FMS falling into five domains, detailed below in Table 4. Each skill is divided into five aspects of performance, and each aspect is rated on a scale of 1 (developing) to 4 (proficient), with a total possible score of 20 for each skill. The assessment was administered by program staff, with two staff assigned to each skill station. We provided a structured training session on assessment procedures, and we assigned the same raters to each skill station in pre- and post-program assessments, to increase consistency. We conducted the assessment in a unique "carnival-style" format, with skill stations distributed around the periphery of a large gymnasium. Participants received a "passport" with instructions to visit each station in any order. Participants then circulated the room to complete each skill. Raters used tablet devices to record scores, with scoring rubrics and rating criteria easily referenced on the screen. An additional station was used to collect participant responses to a modified version of the PLAYself Physical Activity Assessment for Youth (Canadian Sport for Life 2014b). This 18-question self-report survey is an evaluation used to determine a youth's perception of their physical literacy. Modifications to the original tool, made in consultation with the tool's authors, included deletion of 2 subscales (a total of 4 questions) relating to the relative ranking of various types of literacies (literacy, numeracy, and physical literacy) and fitness level. The survey was completed using a tablet device, with staff assistance for all youth aged 6-7 and any older youth requiring assistance.

\section{Data analysis}

Statistical analyses were completed using R 3.6.0 (R Core Team 2018). Participants who completed all 13 FMS and the PLAYself survey at both baseline and post-program were included in the analysis. The five components of each FMS were summed to create a score out of 20 for each of the 13 skills. Skills were summed to create the five domain scores, and these domain scores were summed to create a total FMS score for each participant. PLAYself responses were summed into an environmental subscale and a physical literacy self-perception subscale, using published guidelines (Sport for Life 2014b). An identical 
process was followed for both baseline and post-program data to create skill and domain scores and overall totals for both FMS and PLAYself.

Paired samples t-tests were conducted to compare the baseline FMS total scores, FMS domain scores, and PLAYself subscale scores to post-program scores. Two-way repeatedmeasures analyses of variance (ANOVAs) were conducted to examine the impact of both age and gender on the change in FMS total scores, FMS domain scores, and PLAYself subscale scores. Bivariate correlations were conducted on the FMS total scores and PLAYself subscale scores to assess the relationship between observed physical competency and participants' self-perceptions of PL.

Participants at the $25^{\text {th }}$ and $75^{\text {th }}$ percentiles at baseline were grouped as low and high performers, respectively. Non-parametric Wilcoxon Signed-Rank tests were conducted on FMS total scores and FMS domain scores for both low and high performers, to assess the impact of the 2-week program on participants with the lowest and highest observed physical competency at baseline.

\section{Results}

Forty-five participants (23 boys and 22 girls) ranging in age from 6 to 10 years old completed both baseline and post-program assessments. Participant demographics are reported in Table 1. Attendance data suggests that a two-week intervention is feasible. On average, participants attended 8.02 days of the nine-day intervention. Eight participants missed two days or more, and only one missed more than four days. The study had a research consent and participation rate of $77 \%$, which compares favorably to other similar studies (Johnstone et al. 2019; Aspen Institute 2015).

The mean total FMS score with a breakdown of skill domain mean scores is described in Table 2. Paired samples t-tests showed a significant increase in mean total FMS score from baseline $(M=162.16, S D=26.08)$ to post-program $(M=175.91, S D=28.06), t(44)$ $=4.37, p<.001$. On average, the total FMS score increased 13.76 points $(S D=21.12)$, with 35 participants having a positive change score from baseline to post-program. There was no significant effect of age or gender on the change in total FMS score.

Mean scores for four of the five skill domains increased significantly from baseline to post-program. The Running $(\Delta M=2.71, S D=4.94, t(43)=3.63, p=.001)$ and Balance $(\Delta M=2.54, S D=4.19, t(36)=3.69, p=.001)$ domains had large increases, whereas Upper Body Object Control $(\Delta M=2.82, S D=8.89, t(44)=2.13, p<.05)$ and Lower

Table 1 Demographics

\begin{tabular}{llrr}
\hline Characteristic & & $N$ & $\%$ \\
\hline Age $(M=7.93)$ & & & \\
& 6 & 7 & $16 \%$ \\
& 7 & 8 & $30 \%$ \\
& 8 & 8 & $18 \%$ \\
& 9 & 8 & $18 \%$ \\
Gender & 10 & 23 & $18 \%$ \\
& Male & 21 & $50 \%$ \\
& Female & 1 & $19 \%$ \\
& Unspecified & & $1 \%$ \\
\hline
\end{tabular}


Table 2 FMS individual skills and domains

\begin{tabular}{|c|c|c|c|c|c|}
\hline Domain & Skill & $\Delta M$ & $S D$ & $t$ & $P$ \\
\hline \multirow[t]{3}{*}{ Running } & & 2.71 & 4.94 & 3.63 & .001 \\
\hline & Run there and back & 1.109 & 2.67 & 2.82 & .007 \\
\hline & Run, jump, land & .500 & 2.20 & 1.54 & .13 \\
\hline \multirow[t]{5}{*}{ Locomotor } & & 3.07 & 10.31 & 1.99 & .052 \\
\hline & Crossover & .068 & 2.62 & .17 & .864 \\
\hline & Hop & -.565 & 5.46 & .70 & .486 \\
\hline & Skip & 1.644 & 3.88 & 2.84 & .007 \\
\hline & Jump & 1.907 & 2.51 & 4.99 & $<.001$ \\
\hline \multirow[t]{5}{*}{ Upper body object control } & & 2.82 & 8.89 & 2.13 & .039 \\
\hline & Overhand throw & .783 & 4.39 & 1.21 & .233 \\
\hline & One-handed catch & .532 & 4.94 & .74 & .464 \\
\hline & Hand dribble & .750 & 2.93 & 1.70 & .096 \\
\hline & Strike with stick & .578 & 3.44 & 1.13 & .266 \\
\hline \multirow[t]{3}{*}{ Lower body object control } & & 2.82 & 7.72 & 2.45 & .018 \\
\hline & Kick ball & 1.978 & 5.70 & 2.33 & .024 \\
\hline & Foot dribble & .682 & 2.81 & 1.61 & .115 \\
\hline \multirow[t]{2}{*}{ Balance } & & 2.462 & 4.12 & 3.74 & .001 \\
\hline & Balance walk & 2.462 & 4.12 & 3.74 & .001 \\
\hline Total & & 13.76 & 21.12 & 4.37 & $<.001$ \\
\hline
\end{tabular}

Body Object Control $(\Delta M=2.82, S D=7.72, t(44)=2.45, p<.05)$ had more modest increases. These improvements are characterized by a greater frequency of participants rated as "Competent" or "Proficient" post-program, compared to baseline (see Table 3). There was a significant effect of gender on the mean change in Balance scores, $F(2,34)=$ $3.517, p=.041$. The impact of camp programming on Balance competency was greater in boys $(\Delta M=3.58, S D=3.76)$ than in girls $(\Delta M=1.59, S D=4.53)$. Boys also improved significantly in Running $(p<.01)$, Lower Body Object Control $(p<.01)$, and Balance $(p$ $<.01$ ), with Locomotor and Upper Body Object control increasing non-significantly. By comparison, girls showed non-significant increases in each of the five skill domains. There was no significant effect of age on mean change scores for any of the five skill domains, nor was there a significant interaction between age and gender on mean change scores.

Table 3 Frequency of competence in FMS domains

\begin{tabular}{|c|c|c|c|c|c|c|c|c|}
\hline \multirow[t]{2}{*}{ Domain } & \multicolumn{2}{|c|}{ Developing } & \multicolumn{2}{|c|}{ Emerging } & \multicolumn{2}{|c|}{ Competent } & \multicolumn{2}{|c|}{ Proficient } \\
\hline & Pre & Post & Pre & Post & Pre & Post & Pre & Post \\
\hline Running & $4 \%$ & $0 \%$ & $13 \%$ & $4 \%$ & $76 \%$ & $96 \%$ & $7 \%$ & $0 \%$ \\
\hline Locomotor & $0 \%$ & $0 \%$ & $9 \%$ & $9 \%$ & $78 \%$ & $67 \%$ & $13 \%$ & $24 \%$ \\
\hline Upper body object control & $0 \%$ & $0 \%$ & $11 \%$ & $9 \%$ & $71 \%$ & $53 \%$ & $18 \%$ & $34 \%$ \\
\hline Lower body object control & $4 \%$ & $0 \%$ & $16 \%$ & $27 \%$ & $58 \%$ & $31 \%$ & $22 \%$ & $42 \%$ \\
\hline Balance & $13 \%$ & $5 \%$ & $13 \%$ & $2 \%$ & $38 \%$ & $22 \%$ & $36 \%$ & $71 \%$ \\
\hline
\end{tabular}


Paired samples t-tests showed a significant increase in total PLAYself scores from baseline $(M=1295.85, S D=270.78)$ to post-program $(M=1721.66, S D=325.83), t(40)$ $=14.96, p<.001$. Total PLAYself scores increased 425.80 points $(S D=182.27)$ from baseline to post-program. In particular, self-perceptions of physical competence (PLAYself subscale 2) increased significantly throughout the program, $t(40)=9.87, p<.001$, while the environmental subscale (PLAYself subscale 1) increased non-significantly. The overall PLAYself score, with a breakdown by subscale, is described in Table 4. Bivariate correlations showed a significant relationship at baseline between PLAYself subscale 2 and total FMS scores, $r=.303, p<.05$, but no significant relationship post-program, $r=.212, p>$ .05. No significant relationship was seen between PLAYself subscale one and total FMS score at either baseline or post-program. There was no significant effect of age or gender on PLAYself scores.

Low performers at baseline were primarily 6- and 7-year-olds and scored low across skill domains. High performers at baseline were primarily 10-year-olds and showed high competence in each of the skill domains. Wilcoxon Signed-Rank tests showed a significant impact of the program on total FMS score for low baseline performers $(n=11, p=.013)$, whereas high performers had an increase approaching significance in total FMS scores $(n$ $=11, p=.075)$. The program had a greater impact on participants with lower baseline scores and had more marginal impacts on participants with greater physical literacy at the start of the program.

\section{Discussion}

In this study we explored whether the PL levels of youth facing barriers, aged 6-10, could be increased through the implementation of a 2-week day camp-style program. Our results suggest that the program was able to improve participants' overall FMS as well as their self-perceptions of PL relating to competence, confidence, motivation, and knowledge. These outcomes provide initial evidence that this program is a viable intervention for increasing multiple domains of PL and achieving significant increases in overall PL. The impact was somewhat more substantial among boys, suggesting that the coed camp-style intervention may impact boys and girls differently. The gender-based variation in outcomes warrants further exploration, as the relationship between gender, sport setting, physical literacy, and physical literacy-related interventions has not been explored in depth (Coyne et al. 2019a, b; MacDonald et al. 2018; Mandigo et al. 2008; Zarrett et al. 2019).

The measurement framework applied in the context of this study enabled the practitioners to establish meaningful and measurable changes in PL as operationally defined in the

Table 4 PLAYself subscales

\begin{tabular}{|c|c|c|c|c|c|c|c|c|}
\hline \multirow[t]{3}{*}{ Subscale } & \multirow[t]{3}{*}{$\Delta M$} & \multirow[t]{3}{*}{$S D$} & \multirow[t]{3}{*}{$t$} & \multirow[t]{3}{*}{$p$} & \multicolumn{4}{|c|}{ Correlations } \\
\hline & & & & & \multicolumn{2}{|c|}{$\begin{array}{l}\text { Baseline total } \\
\text { FMS }\end{array}$} & \multicolumn{2}{|c|}{ Post total FMS } \\
\hline & & & & & $r$ & $P$ & $r$ & $p$ \\
\hline 1. Environment & 8.54 & 92.97 & .588 & $<.05$ & .298 & $>.05$ & .172 & $>.05$ \\
\hline $\begin{array}{l}\text { 2. Self-perception of } \\
\text { physical competence }\end{array}$ & 374.40 & 248.73 & 9.871 & $<.001$ & .562 & $<.01$ & .564 & $<.01$ \\
\hline
\end{tabular}


program pedagogy. The design of the measurement framework recognized the coexisting distinction and overlap between FMS and PL and the importance of delineating changes relating to both constructs. The unique carnival-style FMS assessment overcame the limitation of previous studies where demonstration-based movement assessments proved overly time- and resource-intensive; this tactic eliminated the perceived burden of a rigorous FMS assessment among both staff and youth, by shaping this component into a fun and engaging program activity.

It is likely that the outcomes were influenced by several intentional program features associated with positive health outcomes in SFD. A high staff-to-youth ratio with welltrained, caring leaders ensured a consistent presence of nurturing adults (Petitpas et al. 2008; Zarrett et al. 2019). The inclusion of "Leaders in Training" as part of the staff team provided an element of peer mentoring to youth participants, who saw themselves reflected in the demographics of these staff (Hoekman et al. 2019; Zarrett et al. 2019). Interactive games developed specifically for this intervention supported the health-related objective of increasing PL, by encouraging the development and creative use of FMS (Mandigo et al. 2018). Essential to the intervention's success was a clear organizational consensus regarding the organization's goals and model of development, including an operational definition of PL that closely informed the program activities and evaluation framework (LeCrom et al. 2019; Svensson and Hambrick 2016). This stated model of development includes a diverse multi-sport approach for youth aged 6-10 that is likely to foster enjoyment of PA alongside the development of PL (Mandigo et al. 2018).

\section{Limitations}

The measurement framework did not consider rules, tactics, and strategies of movement, which has been proposed as a core element of observed PL (Dudley et al. 2017). The pragmatic, practical approach to measurement applied may also have disproportionately focused on physical and motor competence (Edwards et al. 2018). The sample was relatively small, and the study utilized quantitative methods only. Finally, while overall PA was quantified in minutes, an assessment was not conducted to determine the intensity of activity.

\section{Conclusions and implications}

An intentionally designed two-week SFD day camp program successfully increased PL among youth facing barriers in a North American urban context. In light of the positive findings of this pilot study, next steps for the authors include a comparison to other delivery models, such as weekly after-school or weekend programs, to examine dosage implications; long-term follow-up with participants to explore the program's impact on continued sport participation and future PA levels; and the integration of wearables into the program evaluation framework to interrogate the relationship between the intensity of PA and PL outcomes.

Open Access This article is licensed under a Creative Commons Attribution 4.0 International License, which permits use, sharing, adaptation, distribution and reproduction in any medium or format, as long as you give appropriate credit to the original author(s) and the source, provide a link to the Creative Commons licence, and indicate if changes were made. The images or other third party material in this article are included in the article's Creative Commons licence, unless indicated otherwise in a credit line to the material. If material is not included in the article's Creative Commons licence and your intended use is not 
permitted by statutory regulation or exceeds the permitted use, you will need to obtain permission directly from the copyright holder. To view a copy of this licence, visit http://creativecommons.org/licenses/by/4.0/.

\section{References}

Aspen Institute (2015). Sport for all, play for life: A playbook to get every kid in the game. https://asset s.aspeninstitute.org/content/uploads/2015/01/Aspen-Institute-Project-Play-Report.pdf?_ga=2.24001 1787.922258125.1568823965-1965084233.1568823965.

Barnas, J., \& Ball, S. (2019). The effects of playground zoning on physical activity during recess in elementary-aged children. Medicine \& Science in Sports \& Exercise, 51(Suppl. 6), 514. https://doi. org/10.1249/01.mss.0000562045.96833.7a.

Barnes, J. D., Cameron, C., Carson, V., Chaput, J. P., Faulkner, G. E., Janson, K., et al. (2016). Results from Canada's 2016 ParticipACTION report card on physical activity for children and youth. Journal of Physical Activity and Health, 13(Suppl. 2), S110-S116. https://doi.org/10.1123/jpah.2016-0300.

Bassett-Gunter, R., Rhodes, R., Sweet, S., Tristani, L., \& Soltani, Y. (2017). Parent support for children's physical activity: A qualitative investigation of barriers and strategies. Research Quarterly for Exercise and Sport, 88(3), 282-292. https://doi.org/10.1080/02701367.2017.1332735.

Beets, M. W., Okely, A., Weaver, R. G., Webster, C., Lubans, D., Brusseau, T., et al. (2016). The theory of expanded, extended, and enhanced opportunities for youth physical activity promotion. International Journal of Behavioral Nutrition and Physical Activity. https://doi.org/10.1186/s12966-016-0442-2.

Belanger, K., Tremblay, M. S., Longmuir, P. E., Barnes, J., Sheehan, D., Copeland, J. L., et al. (2016). Physical literacy domain scores in Canadian children meeting and not meeting Canada's physical activity guidelines. Medicine \& Science in Sports \& Exercise, 48(Suppl. 5), 345. https://doi.org/10.1249/01. mss.0000486047.16838.c7.

Bopp, T., \& Roetert, E. P. (2018). Bright spots, physical activity investments that work - Gators in Motion: A holistic approach to sport-based youth development. British Journal of Sports Medicine, 53(24), 1560-1561. https://doi.org/10.1136/bjsports-2018-099528.

Cairney, J., Dudley, D., Kwan, M., Bulten, R., \& Kriellaars, D. (2019). Physical literacy, physical activity and health: Toward an evidence-informed conceptual model. Sports Medicine, 49(3), 371-383. https:// doi.org/10.1007/s40279-019-01063-3.

Cale, L., \& Harris, J. (2018). The role of knowledge and understanding in fostering physical literacy. Journal of Teaching in Physical Education, 37(3), 280-287. https://doi.org/10.1123/jtpe.2018-0134.

Canadian Sport for Life (2014a). Physical literacy assessment for youth: PLAYfun. http://physicalliteracy.ca/ wp-content/uploads/2016/08/PLAYfun_workbook.pdf.

Canadian Sport for Life (2014b). Physical literacy assessment for youth: PLAYself. http://physicalliterac y.ca/wp-content/uploads/2017/01/PLAYself_Workbook.pdf.

Canadian Sport for Life (2017). An introduction to physical literacy. http://physicalliteracy.ca/wp-content/ uploads/2017/05/Introduction-to-Physical-Literacy.pdf.

Carson, V., Chaput, J. P., Janssen, I., \& Tremblay, M. S. (2017). Health associations with meeting new 24-hour movement guidelines for Canadian children and youth. Preventive Medicine, 95, 7-13. https:// doi.org/10.1016/j.ypmed.2016.12.005.

Castelli, D. M., Centeio, E. E., Beighle, A. E., Carson, R. L., \& Nicksic, H. M. (2014). Physical literacy and comprehensive school physical activity programs. Preventive Medicine, 66, 95-100. https://doi. org/10.1016/j.ypmed.2014.06.007.

CIBC \& KidSport (2014). CIBC-KidSport ${ }^{\mathrm{TM}}$ report: Helping our kids get off the sidelines. https://www. kidsportcanada.ca/site/assets/files/10418/cibc_kidsport_report_july_2014_final.pdf.

Coyne, P., Dubé, P., Santarossa, S., \& Woodruff, S. J. (2019a). The relationship between physical literacy and moderate to vigorous physical activity among children 8-12 years. Physical \& Health Education Journal, 84(4), 1-13.

Coyne, P., Vandenborn, E., Santarossa, S., Milne, M. M., Milne, K. J., \& Woodruff, S. J. (2019b). Physical literacy improves with the Run Jump Throw Wheel program among students in grades 4-6 in southwestern Ontario. Applied Physiology, Nutrition, and Metabolism, 44(6), 645-649. https://doi. org/10.1139/apnm-2018-0495.

Dobbins, M., Husson, H., Decorby, K., \& LaRocca, R. L. (2013). School-based physical activity programs for promoting physical activity and fitness in children and adolescents aged 6 to 18. Cochrane Database of Systematic Reviews. https://doi.org/10.1002/14651858.CD007651.pub2.

Donnelly, J. E., Greene, J. L., Gibson, C. A., Smith, B. K., Washburn, R. A., Sullivan, D. K., et al. (2009). Physical activity across the curriculum (PAAC): A randomized controlled trial to promote physical 
activity and diminish overweight and obesity in elementary school children. Preventive Medicine, 49(4), 336-341. https://doi.org/10.1016/j.ypmed.2009.07.022.

Draaisma, M., \& Brown, D. (2018). Ontario government cuts \$25M in funding for specialized school programs. $\quad C B C$ News. https://www.cbc.ca/news/canada/toronto/ontario-education-programs-fundingcuts-1.4948200.

Dudley, D. A. (2015). A conceptual model of observed physical literacy. The Physical Educator, 72(5), 236-260. https://doi.org/10.18666/TPE-2015-V72-I5-6020.

Dudley, D. A., Cairney, J., Wainwright, N., Kriellaars, D., \& Mitchell, D. (2017). Critical considerations for physical literacy policy in public health, recreation, sport, and education agencies. Quest, 69(4), 436-452. https://doi.org/10.1080/00336297.2016.1268967.

Durden-Myers, E. J., Green, N. R., \& Whitehead, M. E. (2018). Implications for promoting physical literacy. Journal of Teaching in Physical Education, 37(3), 262-271. https://doi.org/10.1123/jtpe.2018-0131.

Edwards, L. C., Bryant, A. S., Keegan, R. J., Morgan, K., \& Jones, A. M. (2017). Definitions, foundations and associations of physical literacy: A systematic review. Sports Medicine, 47(1), 113-126. https:// doi.org/10.1007/s40279-016-0560-7.

Edwards, L. C., Bryant, A. S., Keegan, R. J., Morgan, K., Cooper, S. M., \& Jones, A. M. (2018). "Measuring" physical literacy and related constructs: A systematic review of empirical findings. Sports Medicine, 48(3), 659-682. https://doi.org/10.1007/s40279-017-0817-9.

Ennis, C. D. (2015). Knowledge, transfer, and innovation in physical literacy curricula. Journal of Sport and Health Science, 4(2), 119-124. https://doi.org/10.1016/j.jshs.2015.03.001.

Giblin, S., Collins, D., \& Button, C. (2014). Physical literacy: Importance, assessment and future directions. Sports Medicine, 44(9), 1177-1184. https://doi.org/10.1007/s40279-014-0205-7.

Canadian Heritage (2013). Sport participation 2010. http://publications.gc.ca/collections/collection_2013/ pc-ch/CH24-1-2012-eng.pdf.

Government of Ontario (2015). Game ON - The Ontario government's sport plan. http://www.mtc.gov. on.ca/en/publications/Game-ON-The-Ontario-Governments-Sport-Plan.pdf.

Green, N. R., Roberts, W. M., Sheehan, D., \& Keegan, R. J. (2018). Charting physical literacy journeys within physical education settings. Journal of Teaching in Physical Education, 37(3), 272-279. https:// doi.org/10.1123/jtpe.2018-0129.

Haywood, K. M., \& Getchell, N. (2009). Lifespan motor development (5th ed.). Champaign, IL: Human Kinetics.

Hellison, D. (2003). Teaching responsibility through physical activity (2nd ed.). Champaign, IL: Human Kinetics.

Hennessy, E., Hatfield, D. P., Chui, K., Herrick, S., Odalen, C., West, T., et al. (2018). Changes in ability, confidence, and motivation among children in a novel school-based physical literacy intervention. Medicine \& Science in Sports \& Exercise, 50(Suppl. 5), 763. https://doi.org/10.1249/01.mss.00005 38514.53208.43.

Hobin, E., Erickson, T., Comte, M., Zuo, F., Pasha, S., Murnaghan, D., et al. (2017). Examining the impact of a province-wide physical education policy on secondary students' physical activity as a natural experiment. International Journal of Behavioral Nutrition and Physical Activity. https://doi. org/10.1186/s12966-017-0550-7.

Hoekman, M. J., Schulenkorf, N., \& Welty Peachy, J. (2019). Re-engaging local youth for sustainable sport-for-development. Sport Management Review, 22(5), 613-625. https://doi.org/10.1016/j. smr.2018.09.001.

Johnstone, A., Hughes, A. R., Bonnar, L., Booth, J. N., \& Reilly, J. J. (2019). An active play intervention to improve physical activity and fundamental movement skills in children of low socio-economic status: Feasibility cluster randomized controlled trial. Pilot and Feasibility Studies. https://doi.org/10.1186/ s40814-019-0427-4.

Leblanc, A. G., Broyles, S. T., Chaput, J. P., Leduc, G., Boyer, C., Borghese, M. M., et al. (2015). Correlates of objectively measured sedentary time and self-reported screen time in Canadian children. International Journal of Behavioral Nutrition and Physical Activity. https://doi.org/10.1186/s1296 6-015-0197-1.

LeCrom, C. W., Martin, T., Dwyer, B., \& Greenhalgh, G. (2019). The role of management in achieving health outcomes in SFD programmes: A stakeholder perspective. Sport Management Review, 22(1), 53-67. https://doi.org/10.1016/j.smr.2018.09.005.

Liu, J., Xiang, P., Lee, J., \& Li, W. (2017). Developing physically literacy in K-12 physical education through achievement goal theory. Journal of Teaching in Physical Education, 36(3), 292-302. https:// doi.org/10.1123/jtpe.2017-0030. 
Lodewyk, K. R., \& Mandigo, J. L. (2017). Early validation evidence of a Canadian practitioner-based assessment of physical literacy in physical education: Passport for Life. The Physical Educator, 74(3), 441-475. https://doi.org/10.18666/TPE-2017-V74-I3-7459.

Logan, S. W., Robinson, L. E., Wilson, A. E., \& Lucas, W. A. (2012). Getting the fundamental of movement: A meta-analysis of the effectiveness of motor skill interventions in children. Child: Care, Health \& Development, 38(3), 305-315. https://doi.org/10.1111/j.1365-2214.2011.01307.x.

Longmuir, P. E., \& Tremblay, M. S. (2016). Top 10 research questions related to physical literacy. Research Quarterly for Exercise and Sport, 87(1), 28-35. https://doi.org/10.1080/02701367.2016.1124671.

Lyras, A., \& Welty Peachey, J. (2011). Integrating sport-for-development theory and praxis. Sport Management Review, 14(4), 311-326. https://doi.org/10.1016/j.smr.2011.05.006.

MacDonald, D. J., Saunders, T. J., Longmuir, P. E., Barnes, J. D., Belanger, K., Bruner, B., et al. (2018). A cross-sectional study exploring the relationship between age, gender, and physical measures with adequacy in and predilection for physical activity. BMC Public Health. https://doi.org/10.1186/ s12889-018-5893-8.

Mandigo, J., Holt, N., Anderson, A., \& Sheppard, J. (2008). European Physical Education Review, 14(3), 407-425. https://doi.org/10.1177\%2F1356336X08095673.

Mandigo, J., Francis, N., Lodewyk, K., \& Lopez, R. (2009). A position paper for physical literacy for educators. Physical \& Health Education Canada. https://phecanada.ca/sites/default/files/content/ docs/resources/pl_position_paper.pdf.

Mandigo, J., Lodewyk, K., \& Tredway, J. (2018). Examining the impact of a teaching games for understanding approach on the development of physical literacy using the Passport for Life assessment tool. Journal of Teaching in Physical Education, 38(2), 136-145. https://doi.org/10.1123/ jtpe.2018-0028.

McGinn, D. (2016). Experts sound alarm as more schools put phys-ed on back burner. The Globe and Mail. http://www.schoolsport.ca/experts-sound-alarm-as-more-schools-put-phys-ed-on-back-burne $\mathrm{r} /$.

Mitra, R., Cantello, I. D., Buliung, R. N., \& Faulkner, G. E. (2017). Children's activity-transportation lifestyles, physical activity levels and socio-ecological correlates in Toronto, Canada. Journal of Transport \& Health, 6, 289-298. https://doi.org/10.1016/j.jth.2017.03.010.

O'Brien, W., Belton, S., \& Issartel, J. (2015). Promoting physical literacy in Irish adolescent youth: The Youth-Physical Activity Towards Health (Y-PATH) intervention. MOJ Public Health, 2(6), 168173. https://doi.org/10.1080/03323315.2018.1552604.

ParticipACTION (2018). The brain + body equation: Canadian kids need active bodies to build their best brains. The 2018 ParticipACTION report card on physical activity for children and youth. http://participaction.cdn.prismic.io/participaction\%2F38570bed-b325-4fc8-8855-f15c9aebac 12_2018_participaction_report_card_-_full_report_0.pdf.

Petitpas, A. J., Cornelius, A., \& Van Raalte, J. (2008). Youth development through sport: It's all about relationships. In N. L. Holt (Ed.), Positive youth development through sport. London: Routledge.

Physical Activity Guidelines Advisory Committee (2008). Physical activity guidelines advisory committee report, 2008. Washington, DC: US Department of Health and Human Services. https://healt h.gov/paguidelines/2008/report/pdf/CommitteeReport.pdf.

Poitras, V. J., Gray, C. E., Borghese, M. M., Carson, V., Chaput, J. P., Janssen, I., et al. (2016). Systematic review of the relationships between objectively measured physical activity and health indicators in school-aged children and youth. Applied Physiology, Nutrition, and Metabolism, 41(6, Supp1. 3), S197-S239. https://doi.org/10.1139/apnm-2015-0663.

Rauner, A., Mess, F., \& Woll, A. (2013). The relationship between physical activity, physical fitness and overweight in adolescents: A systematic review of studies published in or after 2000. BMC Pediatrics. https://doi.org/10.1186/1471-2431-13-19.

$\mathrm{R}$ Core Team (2018). A language and environment for statistical computing. R Foundation for Statistical Computing. http://www.R-project.org/.

Schulenkorf, N., Sherry, E., \& Rowe, K. (2016). Sport-for-development: An integrated literature review. Journal of Sport Management, 30(1), 22-39. https://doi.org/10.1123/jsm.2014-0263.

Shearer, C., Gross, H. R., Edwards, L. C., Keegan, R. J., Knowles, Z. R., Boddy, L. M., et al. (2018). How is physical literacy defined? A contemporary update. Journal of Teaching in Physical Education, 37(3), 237-245. https://doi.org/10.1123/jtpe.2018-0136.

Sported (2020). What is sport for development? https://sported.org.uk/about-us/what-is-sport-for-devel opment/.

Svensson, P. G., \& Hambrick, M. E. (2016). "Pick and choose our battles" - Understanding organizational capacity in a sport for development and peace organization. Sport Management Review, 19(2), 120-132. https://doi.org/10.1016/j.smr.2015.02.003. 
Svensson, P. G., \& Woods, H. (2017). A systematic overview of sport for development and peace organisations. Journal of Sport for Development, 5(9), 36-48.

Tompsett, C., Burkett, B., \& McKean, M. R. (2014). Development of physical literacy and movement competency: A literature review. Journal of Fitness Research, 3(2), 53-79.

Tremblay, M. S., Barnes, J. D., González, S. A., Katzmarzyk, P. T., Onywera, V. O., Reilly, J. J., et al. (2016a). Global Matrix 2.0: Report card grades on the physical activity of children and youth comparing 38 countries. Journal of Physical Activity and Health, 13(Suppl 2), S343-S366. https://doi. org/10.1123/jpah.2016-0594.

Tremblay, M. S., Carson, V., Chaput, J. P., Connor Gorber, S., Dinh, T., Duggan, M., et al. (2016b). Canadian 24-hour movement guidelines for children and youth: An integration of physical activity, sedentary behaviour, and sleep. Applied Physiology, Nutrition, and Metabolism, 41(6 Suppl. 3), S311-S327. https://doi.org/10.1139/apnm-2016-0151.

Tremblay, M. S., Costas-Bradstreet, C., Barnes, J. D., Barlett, B., Dampier, D., Lalonde, C., et al. (2018a). Canada's Physical Literacy Consensus Statement: Process and outcome. BMC Public Health. https://doi.org/10.1186/s12889-018-5903-x.

Tremblay, M. S., Longmuir, P. E., Barnes, J. D., Belanger, K., Anderson, K. D., Bruner, B., et al. (2018b). Physical literacy levels of Canadian children aged 8-12 years: Descriptive and normative results from the RBC Learn to Play - CAPL project. BMC Public Health. https://doi.org/10.1186/ s12889-018-5891-X.

Trudeau, F., \& Shephard, R. J. (2008). Physical education, school physical activity, school sports and academic performance. International Journal of Behavioral Nutrition and Physical Activity. https:// doi.org/10.1186/1479-5868-5-10.

UNESCO (2015). Quality physical education (QPE): Guidelines for policy makers. https://unesd oc.unesco.org/ark:/48223/pf0000231101.

Whitehead, M. (Ed.) (2010). Physical literacy: Throughout the lifecourse. London: Routledge.

Whitley, M. A., Farrell, K., Wolff, E. A., \& Hillyer, S. J. (2019a). Sport for development and peace: Surveying actors in the field. Journal of Sport for Development, 7(12), 1-15.

Whitley, M.A., Massey, W., Blom, L., Camiré, M., Hayden, L., \& Darnell, S. (2017). Sport for development in the United States: A systematic review and comparative analysis. Laureus USA. https:// www.laureususa.com/wp-content/uploads/2018/07/Final-Report-by-Whitley-et-al..pdf.

Whitley, M. A., Massey, W. V., Camiré, M., Blom, L. C., Chawansky, M., Forde, S., et al. (2019b). A systematic review of sport for development interventions across six global cities. Sport Management Review, 22(2), 181-193. https://doi.org/10.1016/j.smr.2018.06.013.

Whitley, M. A., Massey, W. V., Camiré, M., Boutet, M., \& Borbee, A. (2019c). Sport-based youth development interventions in the United States: A systematic review. BMC Public Health. https://doi. org/10.1186/s12889-019-6387-z.

Wright, E. M., Griffes, K. R., \& Gould, D. R. (2017). Qualitative examination of adolescent girls' sport participation in a low-income, urban environment. Women in Sport and Physical Activity, 25(2), 77-88. https://doi.org/10.1123/wspaj.2016-0002.

Zarrett, N., Cooky, C., \& Veliz, P.T. (2019). Coaching through a gender lens: Maximizing girls' play and potential. Women's Sports Foundation. https://www.womenssportsfoundation.org/wp-content/ uploads/2019/04/coaching-through-a-gender-lens-report-web.pdf.

Publisher's Note Springer Nature remains neutral with regard to jurisdictional claims in published maps and institutional affiliations.

Marika Warner is Director of Research and Evaluation at MLSE LaunchPad (mlselaunchpad.org), a Sport For Development facility for youth facing barriers in downtown Toronto. Marika's portfolio includes program evaluation, longitudinal research, and academic partnerships focusing on physical literacy, positive youth development, and corporate social responsibility in professional sport. Marika holds a BScPT from the University of Alberta and an MSc in Rehabilitation Science from the University of Toronto. Marika is currently partnering with the University of Ottawa, University of Toronto, York University, Ryerson University, Brock University, and the University of Windsor to generate innovative research on individual, community, and population-level outcomes in youth Sport For Development.

Jackie Robinson is Coordinator of Research and Evaluation at MLSE LaunchPad and has been working and researching in the youth sport sector for the last five years in academic and community environments. A lifelong athlete herself, she uses research to support the development of quality sport programming that 
gives youth the opportunity to enjoy sport and movement as much as she does. In her role at MLSE LaunchPad, Jackie works collaboratively with the Sport Programming Team to create and refine program plans around specific Sport For Development outcomes like Physical Literacy. She enjoys making participation in research fun for youth through innovative evaluation methods.

Bryan Heal has 14+ years of community-based participatory research and program evaluation experience, with an emphasis on environments serving youth and vulnerable populations. Bryan manages the research and evaluation agenda for MLSE LaunchPad and provides measurement strategy and capacity building support to youth-serving community organizations from a diverse range of sectors including sport, food, justice, mental health, and education. Prior to this role, Bryan has been an advocate on public policy matters regarding the social determinants of health, having consulted or advised public sector funders and governments, including United Way Toronto, the City of Toronto, Psychiatric Patient Advocate Office, and the International Centre for Migration Health and Development.

Jennifer Lloyd is a youth worker, anti-violence program facilitator, and community organizer. She holds an MSW from Wilfrid Laurier University and is a Registered Social Worker with the Ontario College of Social Workers and Social Service Workers. Jennifer completed an internship with the Research and Evaluation Team at MLSE LaunchPad in 2019-2020.

James Mandigo is Provost and Vice-President of the University of the Fraser Valley. Previously, James was a professor in the Department of Kinesiology within the Faculty of Applied Health Sciences at Brock University. James is a member of the Canadian Sport for Life Leadership Team, Past- President for the Ontario Physical and Health Education Association, and former Ontario representative on the Physical and Health Education's Board of Directors. His current research and development project in the Central American countries of El Salvador and Guatemala explores the role that sport and physical education have in the prevention of youth violence. His research and development activities in this area have been funded by the Canadian Social Science and Humanities Research Council, the International Olympic Committee, and Scotiabank International.

Bess Lennox is Manager of Sport Programming at MLSE LaunchPad. She previously worked on the Community Team at Ontario Basketball and, before that, as a Foreign Service Officer with the Government of Canada. Bess holds a BA from Western University in History and French, and an MA in Public and International Affairs from the University of Ottawa. Bess is an enthusiastic advocate for the positive role that sport can play in the lives of women and girls.

Larkin Davenport Huyer graduated with a MPH in 2018 and a BSc with a specialization in Kinesiology in 2016, both from Queen's University. She spent her undergraduate career competing and training for the varsity and national rowing team; immersing herself in exercise and sport. She has great interest in researching policy and systemic factors and understanding how these affects one's wellbeing. She currently holds a research assistant position at St. Michael's Hospital, Unity Health Toronto, with the Knowledge Translation $\mathrm{Lab}$ and pursing a nursing degree at University of Toronto. 